\title{
A combined analysis of four observational studies evaluating the intraocular pressure-lowering ability and tolerability of bimatoprost $0.01 \%$ in patients with primary open-angle glaucoma or ocular hypertension
}

This article was published in the following Dove Press journal:

Clinical Ophthalmology

6 April 2016

Number of times this article has been viewed

\author{
Annemie Stevens' \\ Milko E Iliev² \\ Leo de Jong ${ }^{3}$ \\ loana Grobeiu ${ }^{4}$ \\ Anton Hommer ${ }^{5}$ \\ 'Department of Ophthalmology, \\ Ghent University Hospital, \\ Ghent, Belgium; ' ${ }^{2}$ epartment of \\ Ophthalmology, University of Bern, \\ Bern, Switzerland; ${ }^{3}$ Department of \\ Ophthalmology, Academic Medical \\ Centre, Amsterdam, the Netherlands; \\ ${ }^{4}$ Allergan Holdings Ltd, Marlow, UK; \\ ${ }^{5}$ Private Office, Vienna, Austria
}

Objective: Combine and evaluate data from four clinical practice studies investigating the intraocular pressure (IOP)-lowering ability, tolerability of and patient adherence to bimatoprost $0.01 \%$ therapy in patients with primary open-angle glaucoma or ocular hypertension.

Methods: Data were combined from four multicenter, prospective, observational studies. Patients $(n=2,593)$ were recruited from 328 sites in Austria, Belgium, Switzerland, and the Netherlands. Assessments were at study entry (baseline) and after 10-14 weeks.

Results: Bimatoprost $0.01 \%$ lowered mean IOP by $5.0 \mathrm{mmHg}$ from baseline to final visit $(P<0.0001)$. Individual IOP goals were achieved in $75.5 \%$ of patients. Results were similar in right and left eyes; right-eye data are presented here for brevity. The greatest mean IOP reduction was $6.7 \pm 4.7 \mathrm{mmHg}(28.8 \%$ reduction from baseline to final visit, $P<0.0001)$ in treatment-naïve patients. Switching to bimatoprost $0.01 \%$ monotherapy from previous monotherapy reduced mean IOP by a further $3.2 \pm 3.6 \mathrm{mmHg}(17.2 \%, P<0.0001)$. Switching to bimatoprost $0.01 \%$ from previous prostaglandin monotherapy reduced mean IOP by $2.9 \pm 3.5 \mathrm{mmHg}(15.5 \%)$, including by $3.1 \pm 3.4 \mathrm{mmHg}(15.8 \%)$ and $3.3 \pm 4.1 \mathrm{mmHg}(16.9 \%)$ for previous latanoprost and travoprost treatment, respectively (all $P<0.0001$ ). IOP reduction in patients previously treated with a fixed combination was $2.7 \pm 4.0 \mathrm{mmHg}(14.2 \%, P<0.0001)$. The most commonly reported adverse events were conjunctival hyperemia $(5.2 \%)$ and eye irritation $(4.7 \%)$. Tolerability was rated as "very good" or "good" by $90.1 \%$ of patients. Adherence was rated by physicians as "better than" or "equal to" previous treatment in $97.2 \%$ of patients.

Conclusion: The combined studies demonstrated in a clinical practice setting, bimatoprost $0.01 \%$ lowered IOP effectively in treatment-naïve and previously treated ocular hypertension and primary open-angle glaucoma patients, and was associated with good tolerability and patient adherence over 12 weeks.

Keywords: bimatoprost $0.01 \%$, intraocular pressure, prostaglandin, bimatoprost, glaucoma treatment, switch therapy

\section{Introduction}

Glaucoma is the second leading cause of blindness worldwide and the most frequent cause of irreversible blindness. ${ }^{1}$ To prevent disease progression and preserve visual function in patients with primary open-angle glaucoma (POAG) or ocular hypertension (OHT), lowering intraocular pressure (IOP) is critical. ${ }^{1-3}$ With the number of glaucoma
Department of Ophthalmology, Ghen University Hospital, De Pintelaan I85, B 9000, Ghent, Belgium

Tel +3292828665

Email annamaria.kestelynstevens@gmail. com 
patients worldwide expected to reach 79.6 million by 2020 , early diagnosis and treatment are imperative to reduce the impact on an individual's quality of life and to reduce the impact on personal and community economic burdens. ${ }^{4}$ The main goal of treatment for glaucoma is to lower the IOP with the aim to preserve visual function. ${ }^{1}$

A topical prostaglandin analog (PGA) is recommended as first-line therapy for many patients with glaucoma as PGAs have well established IOP-lowering efficacy, tolerability, and convenient once-daily dosing. ${ }^{5}$ In a meta-analysis of eight clinical trials, bimatoprost $0.03 \%$ (Lumigan ${ }^{\circledR} 0.03 \%$, Allergan, Inc., Irvine, CA, USA) had statistically greater overall ability to lower IOP compared with latanoprost or travoprost, but it was associated with a higher incidence of conjunctival hyperemia. ${ }^{6}$ Another meta-analysis that included 32 head-to-head clinical trials that studied PGAs and/or timolol found bimatoprost to have the highest IOP-lowering efficacy. ${ }^{7}$ Bimatoprost $0.01 \%$ (Lumigan ${ }^{\circledR} 0.01 \%$, Allergan, Inc.) was developed with the aim of improving tolerability while maintaining a similar IOP-lowering efficacy to bimatoprost $0.03 \%{ }^{8,9}$ Bimatoprost $0.01 \%$ therapy has demonstrated significant IOP-lowering efficacy, good tolerability, and noninferiority compared with bimatoprost $0.03 \%{ }^{8,9}$

The objective was to combine and evaluate data from four studies investigating the IOP-lowering ability, tolerability of and patient adherence to bimatoprost $0.01 \%$ therapy in reallife clinical practice, either as a monotherapy or concurrently with a beta blocker, in patients with POAG or OHT.

\section{Methods}

\section{Study design}

This was a combined analysis of four multicenter, prospective, observational studies. A total of 328 sites in four European countries (Austria, Belgium, Switzerland, and the Netherlands) were identified. The protocol and the case report form were distributed to all physicians, but owing to the observational nature of the study and assessing bimatoprost $0.01 \%$ in a real-life clinical setting, physicians may have deemed some tests unnecessary for their patients and omitted them, returning incomplete forms. In the interests of integrity and transparency, specific sub-analyses were conducted using data for all patients with complete data (eg, a baseline and final visit measurement when the parameter measured was change in IOP). As a result of this, the populations for each analysis are different from each other and from the entire population included in this combined analysis.

Patients were treated with bimatoprost $0.01 \%$ at the discretion of their treating physician and guided by the
Summary of Product Characteristics, which recommends the daily administration of one drop of bimatoprost $0.01 \%$ to each affected eye. ${ }^{10}$ Owing to the observational nature of each study, there was no washout period before commencing bimatoprost $0.01 \%$ therapy.

The primary objective of each individual study was to assess the IOP-lowering ability of bimatoprost $0.01 \%$ as measured by change in IOP from baseline to final visit (10-14 weeks). The target IOP was defined by physicians on an individual basis. Baseline and end-of-study IOP were determined by a single measure as per the physician's usual clinical practice. The secondary objective was to evaluate the safety, tolerability, and treatment compliance of bimatoprost $0.01 \%$ in routine clinical practice. Patients were assessed at baseline and final visit for physicians' evaluation of IOP lowering and tolerability, patient assessment of tolerability, adverse events (AEs), and physicians' assessment of adherence to therapy compared with previous therapy. All data were recorded using the study case report form. At the first visit, additional data for demographics, diagnosis, previous therapies, the reason for prescribing bimatoprost $0.01 \%$ (physicians could select more than one reason), and AEs were recorded. AEs and previous therapies were recorded as free-text entries.

\section{Patients}

Patients included in each study had a diagnosis of POAG or OHT established by their treating physician and were prescribed bimatoprost $0.01 \%$ as monotherapy or concurrently with a beta-blocker therapy. Patients were eligible for inclusion regardless of whether they had received prior IOP-lowering therapy. There were no explicit exclusion criteria, although investigators were guided by the contraindications specified in the Summary of Product Characteristics: hypersensitivity to bimatoprost and any of the excipients, or a previous adverse reaction to benzalkonium chloride. ${ }^{10}$ Participants provided informed consent and each study complied with the principles of Good Clinical Practice and the Declaration of Helsinki.

\section{Analysis}

Data analyses were performed descriptively, including preparation of data listings and summary statistics (extreme values, interquartile ranges, mean and median values, and standard deviations [SDs]) or frequency distribution tables, as appropriate. Data from each of the four identically designed studies were combined and pooled for analysis. Only patients with complete data in the subgroup of interest at both study visits were included for the analysis. Data entry and analysis used the statistical software package SAS, version 9.1.3 
(SAS Institute Inc., Cary, NC, USA) and proprietary software of Syneed Medidata GmbH (Konstanz, Germany).

\section{Results}

All four studies included in this combined analysis took place between April 2010 and March 2013. In total, 2,593 patients were recruited: 419 from Austria (48 sites), 933 from Belgium (117 sites), 387 from Switzerland (79 sites), and 854 from the Netherlands ( 84 sites). As stated previously, owing to the observational nature of each individual study, data were not available for all patients on every parameter assessed. Sub-analyses were conducted using data for all patients with complete datasets; as such the populations for each were different.

The mean duration of the monitoring period was $12 \pm 7.8$ weeks per site. The combined study population included slightly more females than males $(54.3 \%)$ and the mean patient age was $66.7 \pm 12.5$ years. Mean baseline IOP was $21.2 \pm 5.3 \mathrm{mmHg}$ in both eyes, and most patients had a diagnosis of POAG (66.4\%) (Table 1). Although POAG predominantly affected both eyes, $6.0 \%$ of patients had only their right eye affected, and $5.9 \%$ had POAG in their left eye only.

Table I Patients' demographic data at baseline

\begin{tabular}{llll}
\hline Patient characteristics & Mean \pm SD & $\mathbf{n}$ & $\% *$ \\
\hline Age (years) & $66.7 \pm 12.5$ & 2,495 & \\
Male & & 1,169 & 45.1 \\
Female & & 1,407 & 54.3 \\
Diagnosis & & \\
POAG & & 1,826 & 66.4 \\
$\quad$ Both eyes & 1,428 & 78.2 \\
$\quad$ Right eye & 110 & 6.0 \\
$\quad$ Left eye & 108 & 5.9 \\
$\quad$ Not specified & & 180 & 9.9 \\
OHT & 925 & 33.6 \\
$\quad$ Both eyes & & 712 & 77.0 \\
$\quad$ Right eye & 90 & 9.7 \\
$\quad$ Left eye & 65 & 7.0 \\
$\quad$ Not specified & & 58 & 6.3 \\
Mean IOP at baseline (mmHg) & & \\
Right eye & $21.2 \pm 5.3$ & 2,572 & \\
Left eye & $21.2 \pm 5.2$ & 2,575 & \\
Patients on prior therapy & & 1,386 & 53.5 \\
Reason to prescribe bimatoprost 0.01\% & & & \\
Insufficient IOP control on prior therapy & & 917 & 31.4 \\
Insufficient tolerability on prior therapy & & 414 & 14.2 \\
Evidence of disease progression & 331 & 11.3 \\
Lack of adherence to prior therapy & & 101 & 3.5 \\
Other & & 1,157 & 39.6 \\
\hline Ner & & & \\
\hline
\end{tabular}

Note: *Percentages may total more or less than $100 \%$ because of missing data or selection of more than one option for some patients.

Abbreviations: IOP, intraocular pressure; OHT, ocular hypertension; POAG, primary open-angle glaucoma; SD, standard deviation.

\section{Prior therapy}

Prior to the start of each study, a total of $46.5 \%(n=1,207)$ of patients had no previous IOP-lowering treatment. Patients switching from a prior therapy accounted for $53.5 \%(n=1,386)$ of the entire study population (Table 1). Most of the patients with a prior therapy had previously received timolol (41.3\%) or latanoprost (30.3\%). Out of the total study population who switched from a prior therapy, $55.6 \%$ of patients switched to bimatoprost $0.01 \%$ monotherapy and $44.4 \%$ of patients switched to bimatoprost $0.01 \%$ plus a beta blocker. Patients instilling two or more therapies prior to commencement on bimatoprost $0.01 \%$ accounted for $20.2 \%(n=280)$ of the total study population, while $16.9 \%(\mathrm{n}=234)$ of patients were instilling three or more medications.

The most frequent reasons given by physicians for prescribing bimatoprost $0.01 \%$ therapy were insufficient IOP control on prior therapy (31.4\%), insufficient tolerability of prior treatment $(14.2 \%)$, evidence of disease progression (11.3\%), and lack of compliance with prior treatment (3.5\%) (Table 1).

\section{Effect on IOP}

Baseline mean $( \pm \mathrm{SD})$ IOP was $21.2 \pm 5.3 \mathrm{mmHg}(\mathrm{n}=2,572)$ and 21.2 $\pm 5.2 \mathrm{mmHg}(\mathrm{n}=2,575)$ for the right and left eyes, respectively (Table 1). For the subset of patients with complete data for the right eye at first and final visits $(n=2,446)$, the mean $( \pm \mathrm{SD}) \mathrm{IOP}$ was $21.2 \pm 5.3 \mathrm{mmHg}$ at baseline and this was reduced to $16.2 \pm 3.7 \mathrm{mmHg}$ at the final visit, corresponding to a mean reduction of $5.0 \pm 4.6 \mathrm{mmHg}(23.6 \%$; $P<0.0001$ ) (Figure 1A). For the subset of patients with complete data for the left eye at first and final visits $(n=2,460)$, the mean IOP was $21.3 \pm 5.2 \mathrm{mmHg}$ at baseline and was reduced to $16.2 \pm 3.8 \mathrm{mmHg}$ at the final visit, corresponding to a mean reduction of $5.0 \pm 4.7 \mathrm{mmHg}(23.6 \% ; P<0.0001)$ (Figure 1A). Full IOP data for the study population and sub-populations can be found in Table 2 and Figure 1A-C.

The target treatment IOP was defined by physicians on an individual patient basis. Physicians rated IOP-lowering efficiency as "IOP lower than target" or "reached target IOP" in $75.5 \%$ of patients with complete evaluation data $(n=1,909 / 2,530)$. For $15.3 \%$ ( $n=388)$ of patients, IOP decreased but the target IOP was not reached, while IOP did not change or was increased in $9.2 \%(n=233)$ of patients.

Patients who switched from a prior therapy to bimatoprost $0.01 \%$ monotherapy owing to evidence of disease progression experienced a reduction in IOP at the final visit compared with baseline $(6.1 \pm 5.2 \mathrm{mmHg}$ in the right eye $[\mathrm{n}=254]$ and $5.9 \pm 5.3 \mathrm{mmHg}$ in the left eye [n=255], $P<0.0001)$. Patients 

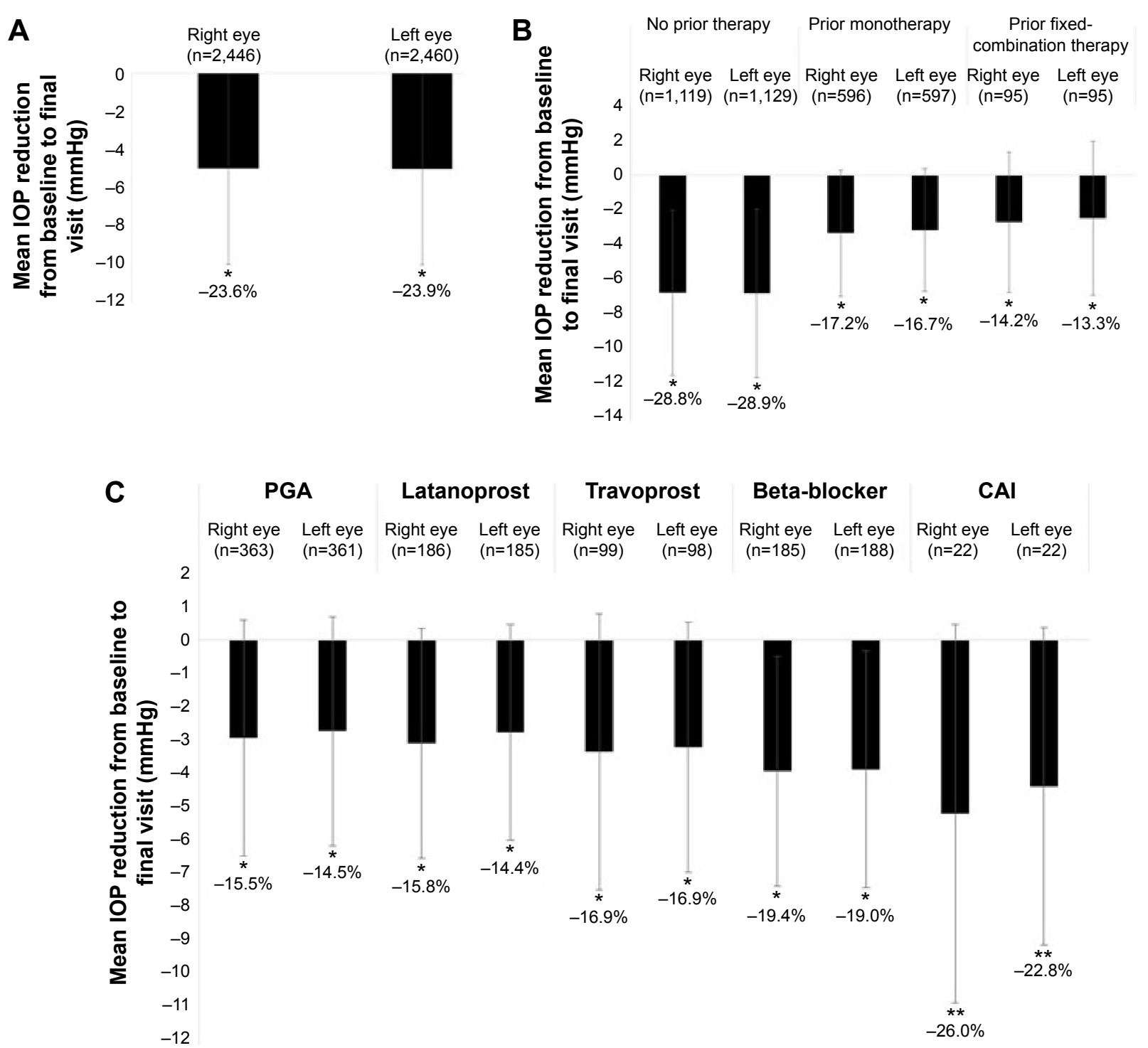

Figure I Mean IOP reductions at the final visit in (A) all patients; (B) patients without prior therapy, patients on a prior monotherapy, and patients on a prior fixedcombination therapy who continued on bimatoprost $0.01 \%$ monotherapy; and $(\mathbf{C})$ patients switching from prior monotherapies to bimatoprost $0.01 \%$ monotherapy. Notes: $* P<0.0001$ and $* * P<0.0003$ comparing IOP from baseline with final visit. Error bars indicate standard deviations. Data from patients with complete data are shown.

Abbreviations: CAI, carbonic anhydrase inhibitor; IOP, intraocular pressure; PGA, prostaglandin analog.

who switched to bimatoprost $0.01 \%$ monotherapy owing to insufficient IOP control on prior treatment also experienced a statistically significant reduction in IOP $(4.3 \pm 3.8 \mathrm{mmHg}$ in the right eye $[\mathrm{n}=649]$ and $4.2 \pm 4.0 \mathrm{mmHg}$ in the left eye [n=651], $P<0.0001$ ), as did those who switched owing to a lack of adherence to $(3.5 \pm 3.5 \mathrm{mmHg}$ in the right eye [ $\mathrm{n}=82]$ and $3.2 \pm 4.5 \mathrm{mmHg}$ in the left eye $[\mathrm{n}=83]$ ) or tolerability problems with their previous therapy $(2.3 \pm 3.5 \mathrm{mmHg}$ in the right eye [n=305] and $2.3 \pm 3.7 \mathrm{mmHg}$ in the left eye [ $\mathrm{n}=308]$ ) (all $P<0.0001$ ).

\section{Tolerability and AEs}

The majority of patients $(2,159 / 2,593,83.3 \%)$ did not report any AEs during treatment with bimatoprost $0.01 \%$.
AEs were recorded for 434 patients (16.7\%) and the most common were conjunctival hyperemia (5.2\%) and eye irritation (4.7\%) (Table 3). Ocular and/or conjunctival hyperemia was reported in $<9.0 \%$ of patients without prior therapy. Where evaluation data were available, bimatoprost $0.01 \%$ therapy was evaluated as "very good" or "good" by $93.8 \%$ of physicians $(n=2,456)$ and $90.1 \%$ of patients $(n=2,442)$ at the final visit.

A total of seven patients recorded serious adverse drug reactions across the four studies. One patient had ocular hyperemia and vein disorder, two patients had ocular hyperemia, two patients had nightmares, one patient had eye irritation, and one patient had dry eye disease. None were considered life-threatening and no patients discontinued 


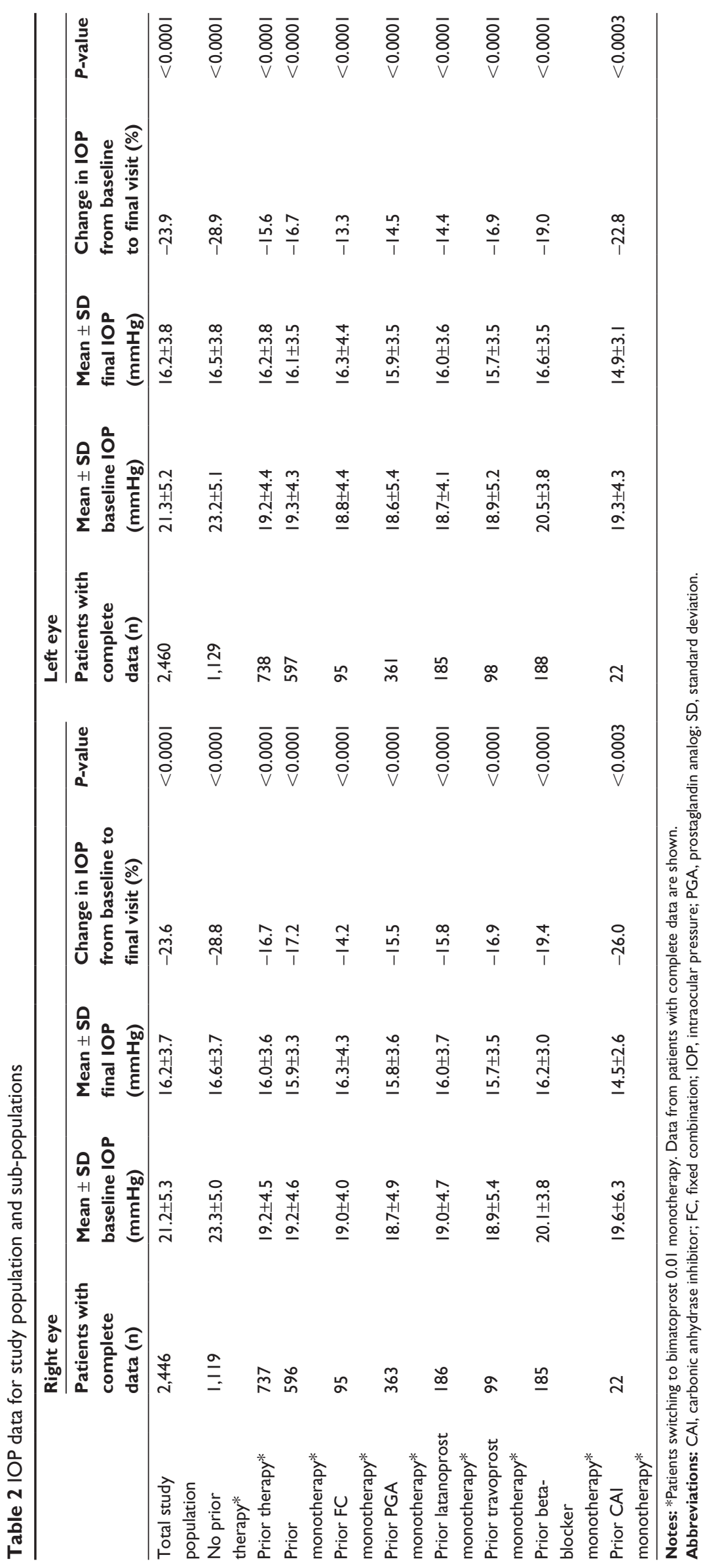


Table 3 Adverse events experienced by $\geq 0.5 \%$ of patients in the total population $(n=2,593)$

\begin{tabular}{lll}
\hline Adverse event & $\mathbf{n}$ & \%* \\
\hline Conjunctival hyperemia & 134 & 5.2 \\
Eye irritation & 123 & 4.7 \\
Ocular hyperemia & 77 & 3.0 \\
Eye pruritus & 63 & 2.4 \\
Eye pain & 24 & 0.9 \\
Blepharal pigmentation & 23 & 0.9 \\
Increased growth of eyelashes & 23 & 0.9 \\
Headache & 13 & 0.5 \\
Dry eye disease & 12 & 0.5 \\
All adverse events & 434 & 16.7 \\
\hline
\end{tabular}

Note: *Some patients $(n=|6|)$ recorded $>\mid$ adverse event.

treatment or left the study. Physicians rated compliance as "better than" or "equal to" previous treatment in $97.2 \%$ of patients $(n=1,269)$. Tolerability was rated as "very good" or "good" by $90.1 \%$ of patients.

\section{Discussion}

This analysis aimed to combine and evaluate the IOP-lowering ability of bimatoprost $0.01 \%$ treatment in patients with POAG or OHT in four studies of clinical practice. Over the course of approximately 12 weeks, the study population, patients with no previous treatment, and patients who switched from a prior therapy to bimatoprost $0.01 \%$ monotherapy, experienced mean IOP reductions in both eyes of $23.8 \%, 28.9 \%$, and $16.2 \%$, respectively. Bimatoprost $0.01 \%$ therapy was well tolerated and AEs were reported in only a minor proportion of patients who completed the study.

This combined analysis of data from four studies confirms the results of previous open-label, observational studies, demonstrating that bimatoprost $0.01 \%$ has good IOP-lowering efficacy and tolerability. ${ }^{8,9,11-14}$ Over 12 weeks in a clinical practice setting, patients with POAG or OHT who were treatment-naïve benefited from an IOP reduction of $30 \%$ with bimatoprost $0.01 \%$ therapy, with $93 \%$ of patients experiencing mild, trace, or no hyperemia. ${ }^{13}$ Bimatoprost $0.01 \%$ was associated with an additional $10 \%-15 \%$ reduction in IOP and was well tolerated in patients who switched from prior therapy in a reallife clinical setting. ${ }^{11}$ In a large observational study comprising $>10,000$ patients, bimatoprost $0.01 \%$ significantly lowered mean IOP by $4.1 \mathrm{mmHg}$ from a baseline of $20.1 \pm 4.5 \mathrm{mmHg}$ in all study patients and by $6.5 \mathrm{mmHg}$ in previously untreated patients..$^{14}$ Additional IOP lowering was seen in patients who received prior monotherapy with beta blockers $(4.6 \mathrm{mmHg})$, latanoprost $(2.8 \mathrm{mmHg})$, travoprost $(3.1 \mathrm{mmHg})$, tafluprost (2.8 $\mathrm{mmHg}$ ), bimatoprost $0.03 \%$ (1.0 $\mathrm{mmHg})$, brinzolamide (4.4 mmHg), and dorzolamide (4.2 mmHg) ${ }^{14}$ Bimatoprost
$0.01 \%$ has demonstrated equivalent IOP-lowering efficacy and improved tolerability compared with bimatoprost $0.03 \%$, including less frequent and severe conjunctival hyperemia. ${ }^{8}, 12$ The study by Katz et al confirmed that bimatoprost $0.01 \%$ is effective and equivalent to bimatoprost $0.03 \%$ in lowering IOP over a 12-month treatment period. ${ }^{8}$

In a previous observational study, bimatoprost $0.01 \%$ demonstrated superior patient adherence compared with bimatoprost $0.03 \% .{ }^{15}$ Adherence in the current study was better than or equal to that of the previous therapy in more than $97 \%$ of patients who switched from a previous therapy to bimatoprost $0.01 \%$.

The four studies in this combined analysis were all openlabel and observational and as such, the data should be interpreted cautiously. Each study relied upon data received from treating physicians and may, therefore, have been influenced by observer bias. Data were recorded at the discretion of the treating physician, and some entries were recorded as free text; as such, errors could have occurred during data collection and interpretation. Most parameters had missing data owing to physicians returning an incomplete panel of results, meaning that there was also the potential for selection bias. Patients were aware of the change in their treatment, which could lead to a Hawthorne effect. ${ }^{16}$ The ability to lower IOP from baseline was assessed, rather than comparing the study medication to a control group. The lack of a control group makes it difficult to establish whether a true effect was seen, or if the results were caused by regression to the mean. There was no washout period between any prior therapies and bimatoprost $0.01 \%$ therapy, as is usual in clinical practice, which may lead to difficulty in determining whether any IOPlowering effect was caused by the previous treatment or the bimatoprost $0.01 \%$. The combined analysis approach taken in this study may not account for between-study heterogeneity (ie, differences between countries, sex, and age), which could mean that the reported results were not representative of the diversity of data collected.

The combination of these four studies provided a large amount of data on the IOP-lowering ability and safety of bimatoprost $0.01 \%$ in a clinical practice setting. Bimatoprost $0.01 \%$ treatment lowered the IOP of most of the treatmentnaïve patients and further lowered the IOP of patients on other treatments, apparently irrespective of the type of treatment. Bimatoprost $0.01 \%$ was also well tolerated and accepted.

\section{Acknowledgments}

The four observational studies were funded by Allergan Ltd. The authors wish to thank Darwin Healthcare 
Communications for writing and editorial support, funded by Allergan Ltd.

\section{Disclosure}

IG is an employee of Allergan Inc. AH has worked as a consultant for Santen and Allergan Inc and has received honorarium for lectures in the past 12 months from Allergan Inc, Pfizer, Santen, and Askin. AS, LJ, and MI report no conflicts of interest in this work.

\section{References}

1. European Glaucoma Society. Terminology and Guidelines for Glaucoma. 4th ed. Savona, Italy: Editrice Dogma; 2014.

2. Heijl A, Leske MC, Bengtsson B, Hyman L, Bengtsson B, Hussein M. Reduction of intraocular pressure and glaucoma progression: results from the Early Manifest Glaucoma Trial. Arch Ophthalmol. 2002;120(10): $1268-1279$.

3. Chauhan BC, Mikelberg FS, Artes PH, et al. Canadian Glaucoma Study: 3. Impact of risk factors and intraocular pressure reduction on the rates of visual field change. Arch Ophthalmol. 2010;128(10):1249-1255.

4. Quigley HA, Broman AT. The number of people with glaucoma worldwide in 2010 and 2020. Br J Ophthalmol. 2006;90(3):262-267.

5. McKee HDR, Gupta MS, Ahad MA, Saldana M, Innes JR. First-choice treatment preferences for primary open-angle glaucoma in the United Kingdom. Eye. 2005;19(8):923-924.

6. Aptel F, Cucherat M, Denis P. Efficacy and tolerability of prostaglandin analogs: a meta-analysis of randomized controlled clinical trials. J Glaucoma. 2008;17(8):667-673.

7. Lin L, Zhao YJ, Chew PT, et al. Comparative efficacy and tolerability of topical prostaglandin analogues for primary open-angle glaucoma and ocular hypertension. Ann Pharmacother. 2014;48(12):1585-1593.
8. Katz LJ, Cohen JS, Batoosingh AL, Felix C, Shu V, Schiffman RM Twelve-month, randomized, controlled trial of bimatoprost $0.01 \%$, $0.0125 \%$, and $0.03 \%$ in patients with glaucoma or ocular hypertension. Am J Ophthalmol. 2010;149(4):661-671.

9. Myers JS, Vold S, Zaman F, Williams JM, Hollander DA. Bimatoprost $0.01 \%$ or $0.03 \%$ in patients with glaucoma or ocular hypertension previously treated with latanoprost: two randomized 12-week trials. Clin Ophthalmol. 2014;8:643-652.

10. Allergan Ltd. Lumigan ${ }^{\circledR} 0.1 \mathrm{mg} / \mathrm{ml}$ Summary of Product Characteristics. Electronic Medicines Compendium (eMC); 2014. Available from http://www.medicines.org.uk/EMC/medicine/22807/SPC/ Lumigan $+0.1 \mathrm{mg}+\mathrm{ml} /$. Accessed February 20, 2015.

11. Crichton AC, Nixon DR, Simonyi S, et al. An observational study of bimatoprost $0.01 \%$ in patients on prior intraocular pressure-lowering therapy: the Canadian Lumigan RC Early Analysis Review (CLEAR) trial. Clin Ophthalmol. 2014;8:1031-1038.

12. Figus M, Nardi M, Piaggi $P$, et al. Bimatoprost $0.01 \%$ vs bimatoprost $0.03 \%$ : a 12 -month prospective trial of clinical and in vivo confocal microscopy in glaucoma patients. Eye. 2014;28(4):422-429.

13. Nixon DR, Simonyi S, Bhogal M, et al. An observational study of bimatoprost $0.01 \%$ in treatment-naive patients with primary open angle glaucoma or ocular hypertension: the CLEAR trial. Clin Ophthalmol. 2012;6:2097-2103.

14. Pfennigsdorf S, Ramez O, von Kistowski G, et al. Multicenter, prospective, open-label, observational study of bimatoprost $0.01 \%$ in patients with primary open-angle glaucoma or ocular hypertension. Clin Ophthalmol. 2012;6:739-746.

15. Campbell JH, Schwartz G, LaBounty B, Kowalski J, Patel VD. Comparison of adherence and persistence with bimatoprost $0.01 \%$ versus bimatoprost $0.03 \%$ topical ophthalmic solutions. Curr Med Res Opin. 2013;29(9):1201-1209.

16. McCarney R, Warner J, Iliffe S, van Haselen R, Griffin M, Fisher P. The Hawthorn Effect: a randomised, controlled trial. BMC Med Res Methodol. 2007;7:30-38.
Clinical Ophthalmology

\section{Publish your work in this journal}

Clinical Ophthalmology is an international, peer-reviewed journa covering all subspecialties within ophthalmology. Key topics include: Optometry; Visual science; Pharmacology and drug therapy in eye diseases; Basic Sciences; Primary and Secondary eye care; Patient Safety and Quality of Care Improvements. This journal is indexed on

Submit your manuscript here: http://www.dovepress.com/clinical-ophthalmology-journal

\section{Dovepress}

PubMed Central and CAS, and is the official journal of The Society of Clinical Ophthalmology (SCO). The manuscript management system is completely online and includes a very quick and fair peer-review system, which is all easy to use. Visit http://www.dovepress.com/ testimonials.php to read real quotes from published authors. 